\title{
Phylogeny of the shanny, Lipophrys pholis, from the NE Atlantic using mitochondrial DNA markers
}

\author{
Sergio Stefanni ${ }^{\mathrm{a}, *}$, Vera Domingues ${ }^{\mathrm{a}, \mathrm{b}}$, Niels Bouton ${ }^{\mathrm{a}}$, Ricardo Serrão Santos ${ }^{\mathrm{a}}$, \\ Frederico Almada ${ }^{\mathrm{b}}$, Vitor Almada ${ }^{\mathrm{b}}$ \\ ${ }^{a}$ IMAR/DOP, University of the Azores, Cais Sta Cruz-9901-862 Horta, Azores, Portugal \\ ${ }^{\mathrm{b}}$ ISPA, Rua Jardim do Tabaco, 34-1149-041 Lisbon, Portugal \\ Received 23 June 2005; accepted 1 July 2005 \\ Available online 24 August 2005
}

\section{Introduction}

The distribution of the shanny includes the NE Atlantic from Norway to Mauritania and the Atlantic islands, with some records in the Western Mediterranean. Although several studies have been carried out on the morphology (Arruda, 1979; Bath, 1976; Lowe, 1843), ecology (Faria and Almada, 2001; Almada and Faria, 2000), ontogeny (Faria et al., 2002), and its diet composition (Maze et al., 1999) not much has been done on the genetics (Guillemaud et al., 2000).

Some authors have drawn attention to morphological differences between Lipophrys pholis of the European continental coasts and the Atlantic islands. One of the first studies to propose subspeciation in L. pholis is Arruda (1979) who identifies unique features for the Azorean shanny.

This observation led Zander (1980) to propose a model of re-colonisation of blennies for the Mediterranean after the Messinian crisis (Hsü et al., 1973). Zander suggests that as the temperature and sea level decreased, those Mediterranean blennies moved towards Atlantic islands. One of these blennies could have been an ancestor of $L$. trigloides which probably gave rise to an ancestor similar to L. pholis. At the end of the glaciation, this "new" species invaded the African and then the European coasts. Finally, Zander justifies the disjunct distribution of the shanny by differences in competition

\footnotetext{
* Corresponding author. Fax: +351 292200411.

E-mail address: sstefanni@notes.horta.uac.pt (S. Stefanni).
}

pressures that lead to the giant race in Madeira (Blennius bufo) and a northern European shanny (B. pholis).

In the present study, we use molecular tools along with meristic counts with the aim of resolving the phylogeny of the shanny. Phylogenetic inferences are based on the analysis of $12 \mathrm{~S}, 16 \mathrm{~S}$, and partial control region (CR) sequences of the mtDNA from three localities along NE Atlantic coast and two Atlantic islands.

\section{Materials and methods}

\subsection{Morphology}

A total of 283 specimens were analysed from the collections listed in Appendix A.

The specimens from "LiphAz1" to "LiphAz5" as well as the larger individual from MMF 24241 were preserved in ethanol therefore they have also been used for the molecular studies.

In addition to meristic counts, for samples from Azores, Portugal mainland, and France, the number of cephalic pores in the nasal area has also been investigated, since their absence was characterising the Azorean population (Arruda, 1979).

\subsection{Molecular analysis}

A total of 28 shannies were included in the comparison of the control region (CR), 12S, and 16S rDNA. Sequences were analysed separately including 20 individuals for the $\mathrm{CR}$ and nine for the $12 \mathrm{~S}$ and $16 \mathrm{~S}$ (one 
individual was shared in all genes studied). Samples were collected from the United Kingdom (Oban and Plymouth), mainland Portugal (Gelfa, Avencas, Amoreira, and Lagos), and two Atlantic islands: Azores (Salão in Fayal) and Madeira (Ponta Delgada). As the projects were carried out at different time, amplifications of CR, 12S, and $16 \mathrm{~S}$ were not all done on the same fishes.

In addition, the sequences of Lipophrys trigloides were included as outgroups.

All fish were fixed in $95 \%$ ethanol before being stored at $-20^{\circ} \mathrm{C}$. mtDNA was extracted from white muscle following the procedure of Sambrook et al. (1989), with slight modifications (Stefanni, 2000). Fragments of the mtDNA including partial CR were amplified using the L-Prol and H-DL1 primers (Ostellari et al., 1996), while for $12 \mathrm{~S}$ and $16 \mathrm{~S}$ the primers used were $12 \mathrm{SF}, 12 \mathrm{SR}, 16 \mathrm{SF}$, and $16 \mathrm{SR}$ (Henriques et al., 2002), respectively. The same primers were also used for sequencing, as described in Stefanni (2000).

\subsection{Sequence alignment and phylogenetic analyses}

All sequences were aligned using SEAVIEW (Galtier et al., 1996) and CLUSTAL X (Thompson et al., 1997). Character congruence between $12 \mathrm{~S}$ and $16 \mathrm{~S}$ was tested using the incongruence-length difference test (ILD; Farris et al., 1995) available in PAUP 4.0 (Swofford, 1999). The null hypothesis of congruence between the two data sets was not rejected $(p=1)$ which led us to analyse the $12 \mathrm{~S}$ and $16 \mathrm{~S}$ rDNA sequences combined in one single fragment.

Hierarchical series of likelihood ratio tests (Huelsenbeck and Rannala, 1997), implemented using MODELTEST 3.06 (Posada and Crandall, 1998) were used to identify the appropriate nucleotide substitution models. Likelihood ratio tests of the model's fit with and without the assumption of a molecular clock were conducted.
Phylogenetic trees of the haplotypes were constructed using PAUP. The trees were rooted with the $L$. trigloides haplotypes as outgroup. The neighbor-joining (NJ) method (Saitou and Nei, 1987) was used to construct a phylogenetic tree from the maximum likelihood (ML) distances estimated under the selected models. The support for internal branches within the NJ tree was assessed using the bootstrap (Felsenstein, 1985) with 1000 replicates. A maximum parsimony (MP) analysis was performed using the default options for heuristic search to find the best MP tree(s). The length $(L)$, consistency index $(\mathrm{CI})$, and retention index $(\mathrm{RI})$ of the MP tree(s) were calculated with parsimony-uninformative sites excluded.

The degree of correlation between geographical distances and genetic differentiation was estimated by regression of a matrix of pairwise linearised $\Phi_{\mathrm{ST}}$ values (Slatkin, 1993), calculated using the program ARLEQUIN 2.000 (Schneider et al., 2000), against a matrix of spatial distribution of the sampling localities. Geographical distances were calculated following the coastal line and for the islands as the shortest distance between one and the other according to the isolation by distance (IBD) model.

\section{Results}

\subsection{Morphology}

\subsubsection{Meristics}

For the mainland samples, frequency distributions of ray counts in the second dorsal (D2) and anal (A) fins show a shift towards higher numbers at higher latitudes (Table 1). Counts of the rays of the first dorsal fins (D1) are stable at 12 with rare exceptions of 11 (Table 1). Counts for rays of the second dorsal and anal fins show high frequencies of 18 and 19. Towards the north the frequency of fishes with 19 fin rays increases, with some individuals in the north having 20

Table 1

Meristics of L. pholis

\begin{tabular}{|c|c|c|c|c|c|c|c|c|c|c|c|}
\hline \multirow[t]{2}{*}{ Location } & \multicolumn{2}{|l|}{ D1 } & \multicolumn{4}{|c|}{ D2 } & \multicolumn{4}{|l|}{ A } & \multirow[t]{2}{*}{$\mathrm{N}$} \\
\hline & XI & XII & 17 & 18 & 19 & 20 & $\mathrm{II}+17$ & $\mathrm{II}+18$ & II + 19 & $\mathrm{II}+20$ & \\
\hline \multicolumn{12}{|l|}{ Mainland } \\
\hline UK & 2 & 17 & 0 & 46 & 69 & 4 & 1 & 27 & 83 & 8 & 119 \\
\hline France & 0 & 15 & 1 & 6 & 8 & 0 & 0 & 4 & 10 & 1 & 15 \\
\hline Portugal & 3 & 11 & 0 & 8 & 6 & 0 & 0 & 4 & 10 & 0 & 14 \\
\hline Morocco & 1 & 69 & 0 & 48 & 22 & 0 & 0 & 32 & 38 & 0 & 70 \\
\hline \multicolumn{12}{|l|}{ Islands } \\
\hline Azores $^{\mathrm{a}}$ & 3 & 26 & 0 & 1 & 26 & 27 & 0 & 0 & 19 & 35 & 54 \\
\hline Madeira & 0 & 5 & 0 & 2 & 3 & 0 & 0 & 2 & 3 & 0 & 5 \\
\hline Savages & 0 & 2 & 0 & 0 & 2 & 0 & 0 & 0 & 2 & 0 & 2 \\
\hline Canaries & 0 & 1 & 0 & 0 & 1 & 0 & 0 & 0 & 1 & 0 & 1 \\
\hline
\end{tabular}

D1, first dorsal fin; D2, second dorsal fin; A, anal fin; N, total number of specimens.

${ }^{a}$ Ray counts for D1 do not include the specimens from the islands of Santa Maria. 
rays. In contrast to the mainland, the Azores population is mainly characterised by 19 and 20 fin rays in both the second part of the dorsal fin and the anal fin (Table 1). At the other oceanic islands (Madeira, Savages, and Canaries) we did not find individuals with 20 fin rays in the second dorsal or anal fin, but samples were too small for statistical comparisons (Table 1). Frequency distributions of fin rays among the other five populations (four mainland and Azores) differ significantly (Kruskall-Wallis test, $p<0.001$ for both D2 and A). The method of multiple comparison (Siegel and Castellan, 1988) revealed that the Azores were different from all other populations $(p<0.05$ for both D2 and A). Furthermore, Morocco differed from the UK in one comparison (D2: $p<0.05$ ), which we interpret as a result of the shift towards higher fin ray counts mentioned above.

\subsubsection{Sensory pores}

The number of sensory pores in the inter-orbital nasal area was identical in all fishes examined. Thus, the extra pore that Arruda (1979) described as a unique feature for the Azorean population was found in mainland populations as well.

\subsection{Genetic analysis}

\subsection{1. $C R$}

All shannies were successfully sequenced and the 20 sequences define 17 haplotypes (GenBank Accession Nos. AY966017-33). All fishes sharing the same haplotype are from the same sampling locality. All sequences correspond to the first hypervariable and part of the central domains of the control region with a length ranging from $450 \mathrm{bp}$ (Oban, UK) to $454 \mathrm{bp}$ (Azores). Five indels are required to align the sequences, giving a total length of $455 \mathrm{bp}$ for all the sequences. Two indels partition the Azorean shanny haplotypes from the others, two partition the Azorean with two and three mainland Portugal haplotypes, respectively, and one is affecting the two Scottish and three Portuguese shannies haplotypes.

The appropriate model of nucleotide substitution was the HKY (Hasegawa et al., 1985) model with invariable sites $(I)$, rate heterogeneity $(G)$, and no clock. The transition/transversion (ti/tv) ratio, proportion of invariable sites (i), and $\gamma$ shape parameter $(\alpha)$ were estimated to be $\mathrm{ti} / \mathrm{tv}=2.9294, i=0$, and $\alpha=0.3877$, respectively. The base frequencies were estimated to be $\mathrm{A}=0.3601, \mathrm{C}=0.1874$, $\mathrm{T}=0.3099$, and $\mathrm{G}=0.1426$.

\subsection{2. $12 S+16 S$}

A total of eight fish were successfully sequenced from which seven haplotypes were defined (GenBank Accession Nos. for 12S and 16S rDNA: AY097015, AY098765-7, AY098825, AY098770, AY0987012-4,
AY0987017, and AY0987019-24). The combined fragment corresponded to a total of 863 and $369 \mathrm{bp}$ for the $12 \mathrm{~S}$ and $494 \mathrm{bp}$ for the $16 \mathrm{~S}$. No indels were required for the alignment and the appropriate model of nucleotide substitution was $\mathrm{K} 80$ with $\mathrm{ti} / \mathrm{tv}=2$.

\subsection{Phylogenetics}

Phylogenetic analysis from CR sequences described by the neighbor-joining (NJ) tree contains 13 internal branches with bootstrap (BS) values greater than 50\% (Fig. 1). The branch separating the Azorean shanny is extremely well supported $(\mathrm{BS}=100)$ while the one including samples from Madeira, mainland Portugal, and Scotland has a much lower value $(B S=72)$. Inside the latter clade, branches with $\mathrm{BS}$ values $>50 \%$ define small ( $n=2$ or 3 ) monophyletic groupings of haplotypes from different sampling localities.

Of the 455 sites considered only 79 are parsimonyinformative. The maximum parsimony (MP) search retained six best MP trees $(L=163, \mathrm{CI}=0.859$, and $\mathrm{RI}=0.832$ ). The strict component consensus tree of the MP trees, which displays all and only those groups found in all the MP trees, resembles the NJ tree. In this tree, the first split separates the Azorean shanny from the monophyletic clade composed by two other groups. One clade which contains the same three haplotypes from mainland Portugal, Avencas (Av10, Av13, and Av17) as presented in the NJ tree, and the second contains haplotypes from all the localities, except for the Azores. The patristic distance between the Azorean

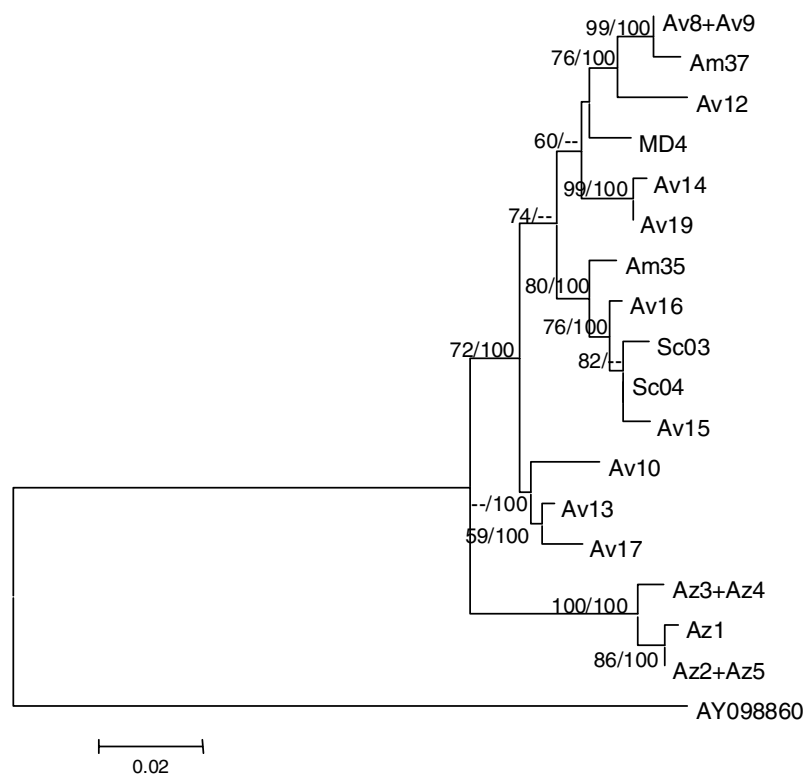

Fig. 1. Neighbor-joining tree constructed from $\mathrm{HKY}+\mathrm{I}+\mathrm{G}$ distances with $\mathrm{ti} / \mathrm{tv}=2.9294, i=0$, and $\alpha=0.3877$. Numbers above internal branches indicate bootstrap values out of 1000 replicates (only if $>50 \%$ ) for NJ and MP strict consensus trees. Az, Azores; Am, Amoreira; Av, Avencas; MD, Madeira; Sc, Oban. 


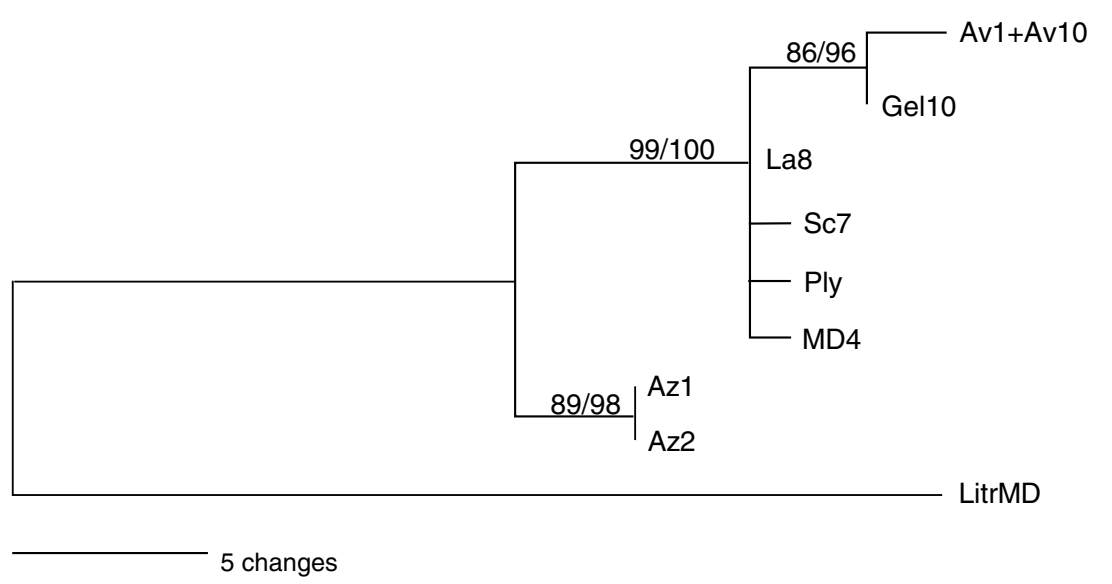

Fig. 2. Maximum parsimony tree for $12 \mathrm{~S}+16 \mathrm{~S}$ with numbers above internal branches indicating bootstrap values out of 1000 replicates (only if $>50 \%$ ) for MP and NJ trees. Az, Azores; Av, Avencas; Gel, Gelfa; La, Lagos; MD, Madeira; Ply, Plymouth; Sc, Oban; Litr, L. trigloides.

clade and the clade containing the remaining samples is between 1.55 and $1.69 \%$.

Not taking into account the Azorean samples, pairwise $\Phi_{\mathrm{ST}}$ values between sites varied between 0.093 (Amoreira-Oban) and 0.935 (Oban-Madeira). The latter is of the same order of magnitude when comparing the Azorean haplotypes with the ones from the other localities. However, $p$ values showed very high significance only when any of the sites is compared with the Azores.

The corrected sequence divergence between the Azores sequences and all the others (Madeira, mainland Portugal, and Scotland) is $4.42 \%$ while the sequence divergence within the two groups is 0.34 and $2.53 \%$, respectively.

The estimates of the number of migrants $\left(N_{\mathrm{m}}\right)$ calculated from the $\Phi_{\mathrm{ST}}$ values (Slatkin, 1993) are much reduced between the two most remote sites $\left(N_{\mathrm{m}}=0.0345\right)$ as well as between the islands of Madeira and Azores $\left(N_{\mathrm{m}}=0.0338\right)$. The reduction in gene flow between localities is not supported by the IBD model and the correlation between geographical distances and genetic differentiation is not significant $(p=0.076)$.

For the phylogenetic analysis of the combined $12 \mathrm{~S}+16 \mathrm{~S}$ fragment, all inference methods converged on the same tree topology (Fig. 2). MP yielded a single most parsimonious tree of 54 steps. All methods resulted in the same samples of shannies as a monophyletic group clearly divided in two clades with very high support values. One clade contains the Azorean fish while in the other clade all the remaining localities are grouped together (mainland Portugal, Madeira, and UK). The patristic distance between the Azorean clade and the one containing the remaining samples is $1.24 \%$.

\section{Discussion}

The phylogenetic analyses and the population genetics strongly support the presence of two groupings of shanny, one for the Azores and one for the mainland Europe which includes the island of Madeira. The clade constituted by the Azorean sample is highly supported by NJ and MP trees using CR and $12 \mathrm{~S}+16 \mathrm{~S}$. Genetics show unique haplotypes for the Azorean shanny. Further support to this finding is the substantial divergence between Azorean sample and the others. Patristic distances between these two groups are 0.77 and $1.58 \%$ for the two fragments at slower rate of evolution (12S and $16 \mathrm{~S}$, respectively) and $1.55-1.67 \%$ for the CR. While in the $12 \mathrm{~S}$ the two Azorean fishes share the same haplotype, in the $16 \mathrm{~S}$ they differ from each other, and the distances between them and the group containing the remaining shannies have an average of $0.61 \%$.

It is important to note that the patristic distance between the Azorean shanny and those from mainland Portugal, UK, and Madeira are of the same order of magnitude (or even higher) than the values between some of recognised distinct species of blennies. For example, the $p$ distance between Parablennius gattorugine and $P$. ruber is $1.6 \%$ and between Lipophrys canevai and $L$. nigriceps is $1.3 \%$ (Almada et al., 2005).

As for $12 \mathrm{~S}$ and $16 \mathrm{~S}$, the $\mathrm{CR}$ also describes unique haplotypes for the Azorean shanny. They are defined by 12 substitutions and four insertions, and are mainly encountered (more than $80 \%$ of them) in the first domain. Within the two clades, the level of nucleotide diversity is very different (Azores: $\pi=0.008$; continental Europe + Madeira: $\pi=0.056$ ) differences which are also reflected in the number of shared haplotypes (Azores: 40\%; continental Europe + Madeira: $7 \%$ ). These rough values also suggest that the population of shanny in the Azores may be very limited in size when compared to the continental one.

When all sampling localities are compared one to another, pairwise values of $\Phi_{\mathrm{ST}}$ result statistically significant only when Azores is included. This is further supported by the lack of correlation between genetic differentiation and geographical distance. 
When comparing $p$ distances from partial $\mathrm{CR}$ sequences of several Lipophrys species (available from GenBank), the lowest value, after the 0.09 between "Azorean" L. pholis and "mainland Portugal" L. pholis, was 0.27 between $L$. adriaticus and $L$. caboverdensis, followed by a 0.32 between $L$. adriaticus and $L$. dalmatinus, and 0.41 between $L$. canevae and $L$. caboverdensis.

Interruption of gene flow in L. pholis between Azores and continental Europe (most probably through Madeira and Canaries islands) might have happened more recently than the Messinian crisis (5.9 Mya) as proposed by Zander (1980). Applying mutational rates compatible with universal molecular clocks, $1 \%$ for region at slow-paced rate (as 12S and 16S), places the split between continental and Azorean shannies at 1.23 Mya, during the early Pleistocene. It is well known that CR yields a mutation rate which is several times faster compared to the rest of the mitochondrial genome (Brown et al., 1993). Taking into account that early Pleistocene is a plausible period for this separation to occur, the mutation rate affecting the $\mathrm{CR}$ of $L$. pholis would range between 2.9 and 5.5\%, values also encountered in other fish species with similar transtion/transversion rate (McMillian and Palumbi, 1997). A reliable calibration of the CR clock for teleosts is provided by the comparison between two amphi-Panamic geminate species of snook (Donaldson and Wilson, 1999), and using this estimate, separation between continental and Azorean shannies occurred about 1 Mya.

Early Pleistocene was characterised by an inter-glacial period with relatively high global temperature and little ice locked up in polar caps (Lambeck et al., 2002). With such warm conditions in the northern hemisphere we might expect to find the anticyclone known as the "Azores High" located further north than today. In such a scenario, we would expect that the trade winds would also be blowing at a higher latitude, maybe from the coasts of southern Europe westward. In this situation, the Azores would receive a constant supply of eggs and larvae from marine organisms breeding in Europe. Such a regular gene flow would possibly have been affected by interruptions, especially during the glaciations that were becoming progressively intense.

During the last glacial maximum, probably several times during the Pleistocene, the temperatures in the European shores would have been so low that L. pholis would have become extinct, re-colonizing from more southern refugia during inter-glacials. On the contrary, at the Azores, the drop in sea surface temperature was apparently much smaller, about $3{ }^{\circ} \mathrm{C}$ (Climap, 1981; Crowley, 1981). As a result, the present population of Azores would have survived there, eventually adapting to long cold periods. This difference in population histories may help to explain the genetic differentiation that we found and the contrast in patterns of meristic characters.
The strong differentiation of the Azorean shanny which is indicated by both, genetic and meristics data and the fact that this fish is extremely rare in the Azores, suggests that the taxonomic and conservation status of this species should be carefully revised.

\section{Acknowledgments}

We thank Norberto Serpa from DOP (University of the Azores) for collection of material in several trips and along those years. S.S. and N.B. are postdoctoral fellows funded by FCT (Foundation for Science and Technology, Portugal, ref. SFRH/BPD/14981/2004 and SFRH/BPD/ $14868 / 2003$, respectively). V.D. is a Ph.D. student with a grant funded by FCT (FCT-PDOC-004/2001). The two research centres are funded by FCT through the pluriannual and programmatic funding scheme (FEDER) as research unit \#531 and research unit \#331/94.

\section{Appendix A. Appendix}

List of collections of L. pholis used for morphological study: BMNH-British Museum of Natural History, London, UK; SMNS-Senckenberg Natural History Museum, Frankfurt, Germany; MMF-Museum Municipal do Funchal, Madeira, Portugal; DOPDepartment of Oceanography and Fisheries, Fayal, Azores, Portugal; RMNH-State Natural History Museum, Leiden, The Netherlands. The specimens were originally collected from the following locations:

1. United Kingdom, 119 specimens: BMNH 47015; $n=11$, Devon; $n=2$, Loch Kishorn; $n=3$, Isle of Lewis-Hebrides; $n=28$, Pembrokeshire; $n=5$, Bude-Cornwall; $n=15$, Eastborne-Sussex; $n=1$, Mullet Peninsula; $n=2$, Pembrokeshire; $n=3$, Orkney; $n=4$, Isle of Mann; $n=3$, Brighton; $n=13$, Rosscarbery Bay; $n=13$, Lannacombe Bay; $n=5$, Guernsey; BMNH 47020, $n=11$, Cornwall.

2. France, 15 specimens: BMNH 47020; $n=10$, Roscoff-Brittany; DOP LIP PHO Fr 1-3, $n=3$, BegMeil-Brittany; RMNH 23844, $n=1$, Roscoff-Britanny; RMNH 23864, $n=1$, Roscoff-Brittany.

3. Morocco, 70 specimens: SMNS $13541 n=24$, Tan Tan; SMNS 13532, $n=1$, Agdu; SMNS 13540, $n=8$, $15 \mathrm{~km}$ south of Tan Tan; SMNS 13506, $n=9$, Cap Rhin; SMNS 13538, $n=10$, Tarfaya; SMNS 13536, $n=5$, Sidi Ifni; $13544, n=13$, Flayounne.

4. Portugal mainland, 14 specimens: DOP LIP PHO Parede $1-14 ; n=14$, Parede.

5. Madeira Island, five specimens: BMNH 1863.9.10.12 $n=3$, Lowe 1863; MMF $22421 n=2$.

6. Porto Santo Island, 1 specimen: RMNH 29592, south west coast. 
7. Savages Iles, two specimens DOP LIP PHO Selvagem $1, n=1$, Selvagem Grande; MMF $201 n=1$, Selvagem Islands.

8. Azores islands (Central group: Fayal and Pico islands), 29 specimens: BMNH 19870, $n=1$, Porto de Salão, Fayal; DOP LIP PHO Az 1-2, Porto de Salão, Fayal, Clipe-project; DOP LIP PHO Az 3-5, Porto de Salão, Fayal; DOP LIP PHO Az 6-25, north coast Fayal; DOP 161-395-LIP PHO-(6;1) $n=3$, São Roque, Pico, Expedition Azores 89; (Oriental group: São Miguel and Santa Maria islands), 27 specimens: DOP LIP PHO Santa Maria 1-25, $n=25$ (lost during transfer of collection); RMNH 35033, $n=1$, Baia São Lourenço, Santa Maria; RMNH 35032, $n=1$, south coast São Miguel.

9. Canary Islands, one specimen: DOP 132-395-LIP PHO-(6;1), Tenerife Norte.

\section{References}

Almada, V., Faria, C., 2000. Experimental study on substratum preferences of early juvenile shanny, Lipophrys pholis (Pisces: Blenniidae). Journal of the Biological Association of the United Kingdom 80, 1143-1144.

Almada, F., Almada, V.C., Guillemaud, T., Wirtz, P., 2005. Phylogenetic relationships of the North-eastern Atlantic and Mediterranean blenniids. Biological Journal of the Linnean Society. (in press).

Arruda, L.M., 1979. On the study of a sample of fish captured in the tidal range at the Azores. Boletim da Sociedade Portuguesa de Ciências Naturais 19, 5-36.

Bath, H., 1976. Revision der Blenniini. Senckenbergiana Biologica 57 (4/6), 167-234.

Brown, J.R., Beckenbach, A.T., Smith, M.J., 1993. Intraspecific DNA sequence variation of the control region of white sturgeon (Acipenser transmontanus). Molecular Biology and Evolution 10, 326-341.

Climap Project Members, 1981. Seasonal reconstructions for the earth's surface at the last glacial maximum, GSA Map \& Chart Serv., MC-36, Boulder, Geological Society of America, Colorado.

Crowley, T.J., 1981. Temperature and circulation changes in the eastern north-atlantic during the last 150,000 years - evidence from the planktonic foraminiferal record. Marine Micropaleontology 6, 97-129.

Donaldson, K.A., Wilson, R.R., 1999. Amphi-panamic geminates of shook (Percoidei: Centropomidae) provide calibration of the divergence rate in the mitochondrial DNA control region of fishes. Molecular Phylogenetics and Evolution 13, 208-213.

Faria, C., Almada, V., 2001. Microhabitat segregation in three rocky intertidal fish species in Portugal: does it reflect intraspecific competition?. Journal of Fish Biology 58, 145-159.

Faria, C., Borges, R., Gil, F., Almada, V.C., Gonçalves, E.J., 2002. Embryonic and larval development of Lipophrys pholis (Pisces: Blenniidae). Scientia Marina 66, 21-26.

Farris, J.S., Källersjö, M., Kluge, A.G., Bult, C., 1995. Constructing a significance test for incongruence. Systematic Biology 44, 570-572.

Felsenstein, J., 1985. Confidence limits on phylogenies: an approach using the bootstrap. Evolution 39, 783-791.

Galtier, N., Gouy, M., Gautier, C., 1996. SEAVIEW and PHYLO_WIN: two graphic tools for sequence alignment and molecular phylogeny. Computer Applications in the Biosciences 12, 543-548.

Guillemaud, T., Almada, F., Santos, R.S., Cancela, M.L., 2000. Interspecific utility of microsatellites in fish: a case study of (CT)(n) and (GT)(n) markers in the shanny Lipophrys pholis (Pisces: Blenniidae) and their use in other blennioidei. Marine Biotechnology 2, 248-253.

Hasegawa, M., Kishino, H., Yano, T.-A., 1985. Dating of the humanape splitting by a molecular clock of mitochondrial DNA. Journal of Molecular Evolution 22, 160-174.

Henriques, M., Lourenço, R., Almada, F., Calado, G., Gonçalves, D., Guillemaud, T., Cancela, M.L., Almada, V.C., 2002. A revision of the status of Lepadogaster lepadogaster (Pisces:Gobiesocidae) sympatric sub-species or a long misunderstood blend species?. Biological Journal of the Linnean Society 76, 327-338.

Hsü, K.J., Ryan, W.B.F., Cita M.B, 1973. Late Miocene dessication of the Mediterranean. Nature 242, 240-244.

Huelsenbeck, J.P., Rannala, B., 1997. Phylogenetic methods come of age: testing hypotheses in an evolutionary context. Science 276, 227-232.

Lambeck, K., Esat, T.M., Potter, E.K., 2002. Links between climate and sea levels for the past three millions years. Nature 419, 199-206.

Lowe, R.T., 1843. Notices of fishes newly observed or discovered in Madeira during the years 1840,1841, and 1842. Proceedings of the Zoological Society of London 11, 81-95.

Maze, R.A., Dominguez, J., Perez-Cardenal, D., 1999. Diet of Lipophrys pholis (L.) (Teleostei, Blenniidae) in Cantabrian coastal waters (Spain). Acta Oecologica-International Journal of Ecology 20, 435-448.

McMillian, W.O., Palumbi, S.R., 1997. Rapid rate of control-region evolution in Pacific butterflyfishes (Chaetodontidae). Journal of Molecular Evolution 45, 473-484.

Ostellari, L., Bargelloni, L., Penzo, E., Patarnello, P., Patarnello, T., 1996. Optimization of single-strand confirmation polymorphism and sequence analysis of the mitochondrial control region in Pagellus bogaraveo (Sparidae, Teleostei): rationalized tools in fish population biology. Animal genetics 27, 423-427.

Posada, D., Crandall, K.A., 1998. Modeltest: testing the model of DNA substitution. Bioinformatics 14, 817-818.

Saitou, N., Nei, M., 1987. The neighbour-joining method: a new method for reconstructing phylogenetic trees. Molecular Biology and Evolution 4, 406-425.

Sambrook, J., Fritsch, E.F., Manitais, T., 1989. Molecular Cloning: A Laboratory Manual, second ed. Cold Spring Harbor Laboratory Press, New York.

Schneider, S., Roessli, D., Excoffier, L., 2000. ARLEQUIN, version 2.000: a software for population genetics data analysis. Genetics and Biometry Laboratory, University of Geneva, Switzerland.

Siegel, S., Castellan Jr., N.J., 1988. Nonparametric Statistics for the Behavioural Sciences. McGraw-Hill, New York.

Slatkin, M., 1993. Isolation by distance in equilibrium and nonequilibrium populations. Evolution 47, 264-279.

Stefanni, S., 2000. A multidisciplinary investigation of intraspecific variation in the European Sand Goby, Pomatoschistus minutus (Pallas) (Teleostei: Gobiidae). Ph.D. Thesis, University of Bristol.

Swofford, D.L., 1999. PAUP*: Phylogenetic Analysis Using Parsimony (and Other Methods), Version 4.0b. Sinauer Associates, Sunderland, Massachusetts.

Thompson, J.D., Gibson, T.J., Plewniak, F., Jeanmougin, F., Higgins, D.G., 1997. The Clustal X windows interface: flexible strategies for multiple sequence alignment aided by quality tools. Nucleic Acids Research 24, 4876-4882.

Zander, C.D., 1980. Zoogeography and speciation of Mediterranean blennioids (Perciformes, Pisces). Journées Etud. Systém. Et Biogéogr. Médit.-Cagliari, C.I.E.S.M., 33-38. 